\title{
Validation and trend analysis of ECV soil moisture data on cropland in North China Plain during 1981-2010
}

\author{
Sisi Wang ${ }^{\mathrm{a}, \mathrm{b}}$, Xingguo Mo ${ }^{\mathrm{a}, *}$, Suxia Liu ${ }^{\mathrm{a}}$, Zhonghui Lin ${ }^{\mathrm{a}}$, Shi Hu${ }^{\mathrm{a}}$ \\ ${ }^{a}$ Key Laboratory of Water Cycle and Related Land surface Processes, Institute of Geographic Sciences and Natural Resources Research, Chinese Academy of \\ Sciences, Beijing 100101, China \\ b University of Chinese Academy of Sciences, Beijing 100049, China
}

\section{A R T I C L E I N F O}

\section{Article history:}

Received 31 March 2015

Received in revised form 15 October 2015

Accepted 16 October 2015

Available online 30 October 2015

\section{Keywords:}

Remotely sensed soil moisture

Trend analysis

Cropland

Climatic factors

\begin{abstract}
A B S T R A C T
Global time series of the Essential Climate Variable (ECV) soil mositure (SM) is being developed from passive and active satellite microwave sensors at a coarse spatial resolution with Climate Change Initiative program funded by European Space Agency. This study aims to validate the reliability of ECV SM dataset, and attempts are made to analyze SM trends in cropland. Firstly, in-situ SM measurements during crop growing seasons from 1992 to 2010 for 228 stations across China and 21 stations over cropland of North China Plain (NCP) were employed to validate ECV SM product. Then, the spatiotemporal variations of ECV SM were analyzed during growing period of winter wheat (April-June) and summer maize (July-September) from 1981 to 2010 in NCP. Finally, the possible relationship between SM, precipitation, evapotranspiration and NDVI were explored. Results showed that ECV SM could generally capture the seasonal SM dynamics. The average triple collocation random error of ECV SM in China was $0.052 \mathrm{~m}^{3} \mathrm{~m}^{-3}$ while the error in cropland ranged from 0.003 to $0.156 \mathrm{~m}^{3} \mathrm{~m}^{-3}$. The averaged Spearman correlation coefficient between ECV SM and all in-situ observations was $0.42(p<0.01)$ in China and $0.43(p<0.01)$ for cropland over NCP. Spatially, ECV SM was decreasing in most areas during wheat season, whereas the trends of ECV SM were positive in south and negative in north during maize season in NCP, being consistent with the precipitation fluctuation. Overall, ECV SM is potentially suitable for trend analysis in NCP and its validations and analysis will be helpful for further enhancement of the ECV SM product.
\end{abstract}

(c) 2015 Elsevier B.V. All rights reserved.

\section{Introduction}

Soil moisture (SM) is one of the most important variables in water cycle linking with energy exchange and mass transport between land surface and atmosphere. It plays an essential role to control the vegetation growth through biogeochemical and biogeophysical processes such as evapotranspiration (ET), runoff, infiltration, regional carbon and nitrogen cycles (Grayson et al., 1997; Li and Rodell, 2013; Orth and Seneviratne, 2013). Meanwhile, the spatiotemporal pattern of SM is closely related to the seasonal variation of precipitation, transpiration and land use type (Mahmood and Hubbard, 2003; Savva et al., 2013). Thus, accurate measurement of SM and monitoring its conditions are of great

\footnotetext{
* Corresponding author. Fax: +86 01064889307

E-mail addresses: wangss.13b@igsnrr.ac.cn (S. Wang), moxg@igsnrr.ac.cn (X. Mo), liusx@igsnrr.ac.cn (S. Liu), linzh@igsnrr.ac.cn (Z. Lin), hus.08b@igsnrr.ac.cn (S. Hu).
}

importance for agricultural industry and water resource management.

The high variability of SM stimulates a number of studies to explore the mechanism of spatiotemporal patterns of SM at regional scale (Cho and Choi, 2014; Qiu et al., 2014; Qiu et al., 2001). Remote sensing technology, especially microwave sensors, has been used for monitoring the spatiotemporal pattern of SM widely (Choi, 2012; Juglea et al., 2010; Liu et al., 2012; Rebel et al., 2012; Wagner et al., 2006). And many global SM products have been retrieved with different remote sensing sensors, such as Advanced SCATterometer (ASCAT) (Figa-Saldaña et al., 2002), Advanced microwave scanning radiometer-earth observing system (AMSR-E) sensors (Jackson et al., 2010) and multi-satellite surface SM dataset (SM-MW) (Dorigo et al., 2012). Generally, the reliabilities of these SM products are assessed by comparing them with ground measurements or/and model simulations (Albergel et al., 2013; Brocca et al., 2011; Qiu et al., 2013). However, the application of these products is limited due to insufficient validation in different regions, and it is necessary to carry out more validation over different climate zones. 

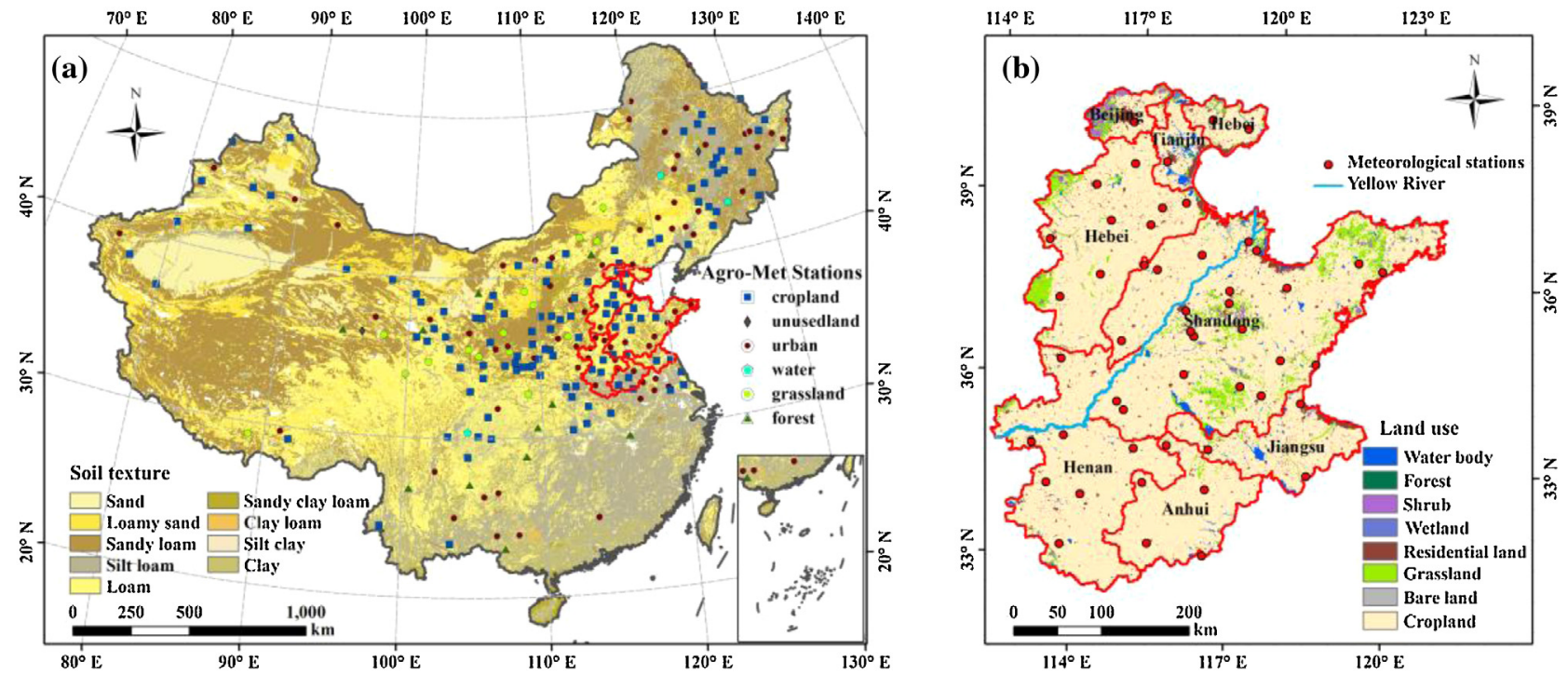

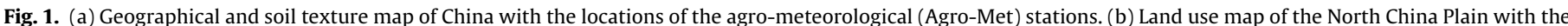

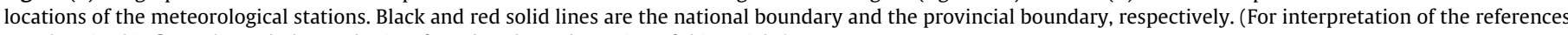
to colour in this figure legend, the reader is referred to the web version of this article.)

The analysis of long time series data is helpful for identifying the trends of natural variables (Leroy et al., 2008; Santer et al., 2011). However, the time span of the remote sensing products is usually short, which limits our knowledge for clarifying the effect of human activities on the climatic variables. In order to generate a consistent long-term SM record, the Essential Climate Variable (ECV) SM product was supplied within the framework of the European Space Agency (ESA) Water Cycle Multi-mission Observation Strategy (WACMOS) and Climate Change Initiative (CCI) project by blending four passive and two active microwave satellite-based retrievals (Liu et al., 2012, 2011b) covering the period from 1979 to 2013 at the global scale with the spatial resolution of $0.25^{\circ}$. The ECV SM dataset was produced from sensors with different temporal and spatial resolution, center frequencies, band-width, radiometric accuracy, observation principle and calibration method (Albergel et al., 2013; Dorigo et al., 2012; Liu et al., 2012). Thus, the reliabilities and potential application of this product need to be analyzed and evaluated. By comparing with model predicted SM, Dorigo et al. (2012) found the most prominent trend patterns in ECV SM were line with the trends of modeled SM from GLDAS-Noah and ERA Interim, and GPCP precipitation. Pratola et al. (2014) recently indicated that ECV SM data were highly correlated with in-situ measurements with correlation coefficient $r>0.6(p<0.025)$. ECV SM in Sahelian region showed a good performance on inter-annual and intra-annual variations of SM and precipitation dynamics (Loew et al., 2013). So far as, there are still some limitations and uncertainties in the merged dataset (Dorigo et al., 2012, 2015; Liu et al., 2012), such as: (1) blending process of ECV SM slightly decreased the precision of the merged datasets with respect to the individual input datasets before blending; (2) given the lower quality and lessstable satellite instrumentation and the heterogeneity in ground samplings, the uncertainty of ECV SM increased in earlier periods; and (3) the ECV SM's retrieval algorithms were sensitive to topography, surface water, and vegetation.

Remotely sensed SM can only detect the water in upper few centimeters of the soil, while the water exchange usually happens in the deep soil layer. For example, roots which absorbed water for transpiration often grow in $0-150 \mathrm{~cm}$ or deeper soil layer. Normalized difference vegetation index (NDVI) as proxy of vegetation development should reflect potentially long-term changes in root- zone SM. Some studies found that the correlation between remotely sensed SM and NDVI was complicated (Dorigo et al., 2012). Liu et al. (2011a) stated that NDVI reacted more directly to changes in available water in crops than bushes and trees. As root-zone SM at large scale is onerous to obtain, remotely sensed SM is taken as a proxy. However, it is required to analyze the relationship between ECV SM and NDVI to determine whether ECV SM is suitable to study structural moisture changes in the root layer in cropland.

In this study, ECV SM dataset of 30 years (1981-2010) was verified with in-situ measurements and simulated time series from an ecohydrological (VIP) model, and used to detect the trend of SM in cropland over the North China Plain (NCP). More specifically, the purposes are:

(1) Validating the accuracy of ECV SM using in-situ SM measurements and model simulated SM by triple collocation method.

(2) Detecting and comparing the spatiotemporal variability, trends between the ECV SM and the model simulated SM in the growing seasons.

(3) Analyzing the correlations between ECV SM and NDVI to reveal SM effect on vegetation growth.

\section{Materials and methods}

\subsection{Study area}

NCP is located in the eastern part of China, extending from latitude $32^{\circ} 00^{\prime} \mathrm{N}$ to $40^{\circ} 24^{\prime} \mathrm{N}$ and longitude $112^{\circ} 48^{\prime} \mathrm{E}$ to $122^{\circ} 45^{\prime} \mathrm{E}$ (Fig. 1) with an area of $33 \times 10^{4} \mathrm{~km}^{2}$ and average elevation of $50 \mathrm{~m}$ above sea level. It is one of the most important granaries of the country. The region has a typical temperate and monsoonal climate with annual mean air temperature of $8-15^{\circ} \mathrm{C}$. The annual precipitation (PPT) distributes non-evenly among seasons ranging from 500 to $1000 \mathrm{~mm}$ and more than $70 \%$ of PPT events occur in summer during the maize growing season. Both temperature and PPT decrease gradually from southeast to northwest. The prevailing doublecropping system is winter wheat (Triticum aestivum $L$.) and summer maize (Zea mays L.). Due to insufficient PPT in spring, the supplemental irrigation for winter wheat is required to obtain optimum yield. NCP suffers from serious water shortage and environmen- 
$114^{\circ} \mathrm{E} \quad 117^{\circ} \mathrm{E} \quad 120^{\circ} \mathrm{E} \quad 123^{\circ} \mathrm{E} \quad 114^{\circ} \mathrm{E} \quad 117^{\circ} \mathrm{E} \quad 120^{\circ} \mathrm{E} \quad 123^{\circ} \mathrm{E} \quad 114^{\circ} \mathrm{E}$
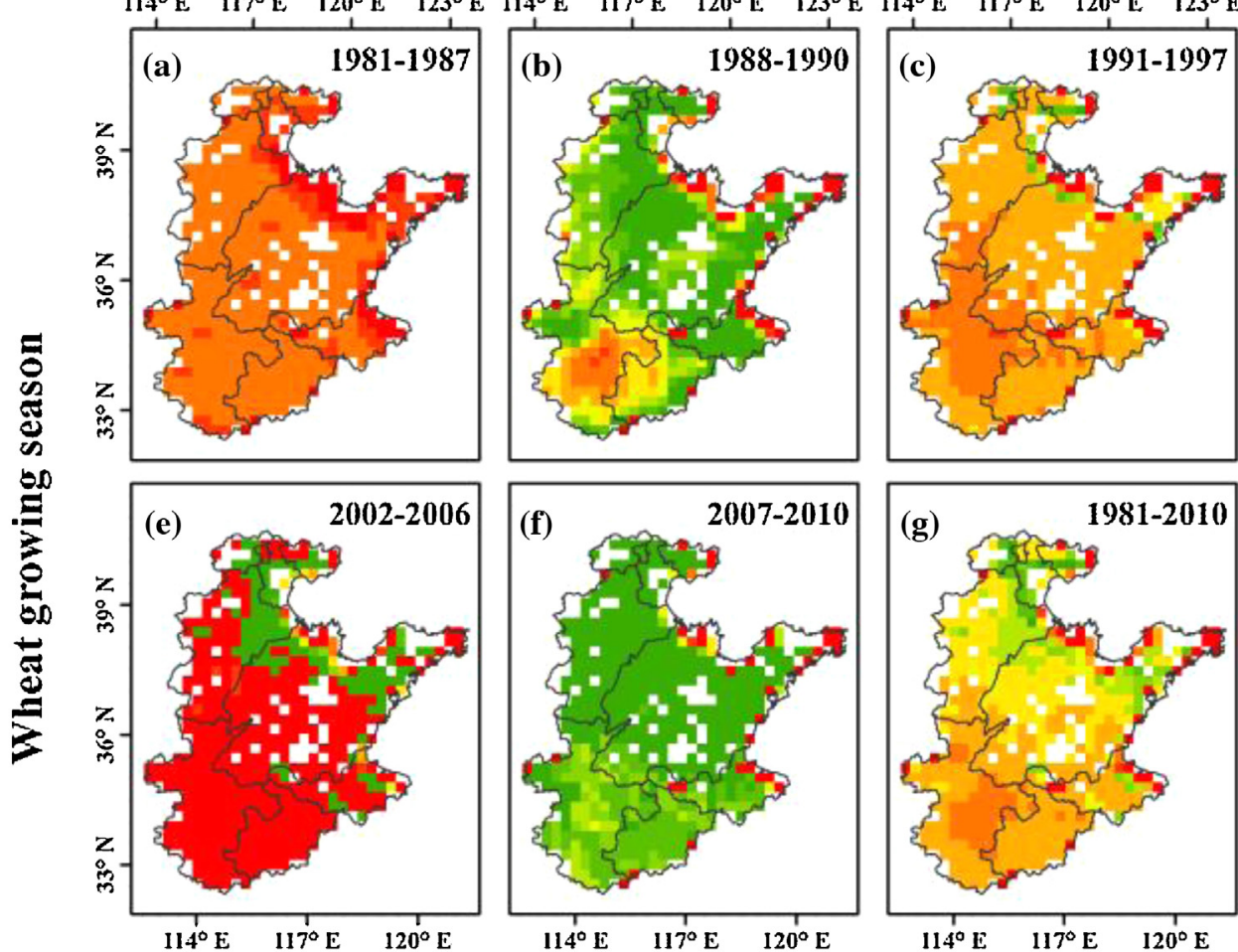

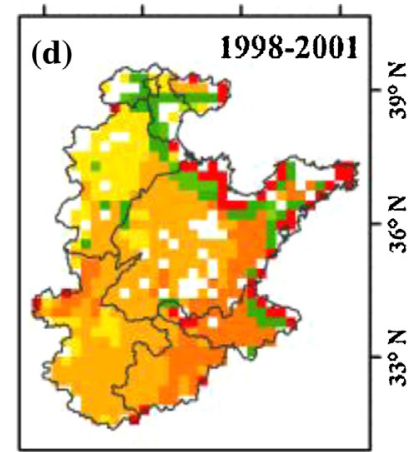

[\%]

50

40

30

20

10

$114^{\circ} \mathrm{E} \quad 117^{\circ} \mathrm{E} \quad 120^{\circ} \mathrm{E} \quad 123^{\circ} \mathrm{E} \quad 114^{\circ} \mathrm{E} \quad 117^{\circ} \mathrm{E} \quad 120^{\circ} \mathrm{E} \quad 123^{\circ} \mathrm{E}$

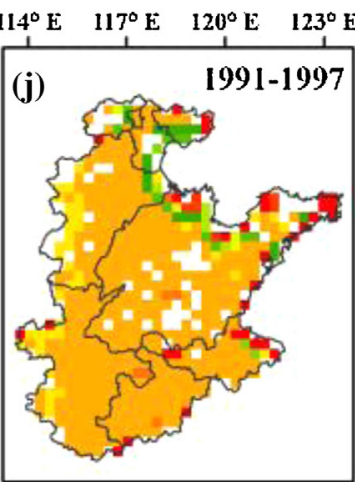

$114^{\circ} \mathrm{E} \quad 117^{\circ} \mathrm{E} \quad 120^{\circ} \mathrm{E} \quad 123^{\circ} \mathrm{E}$
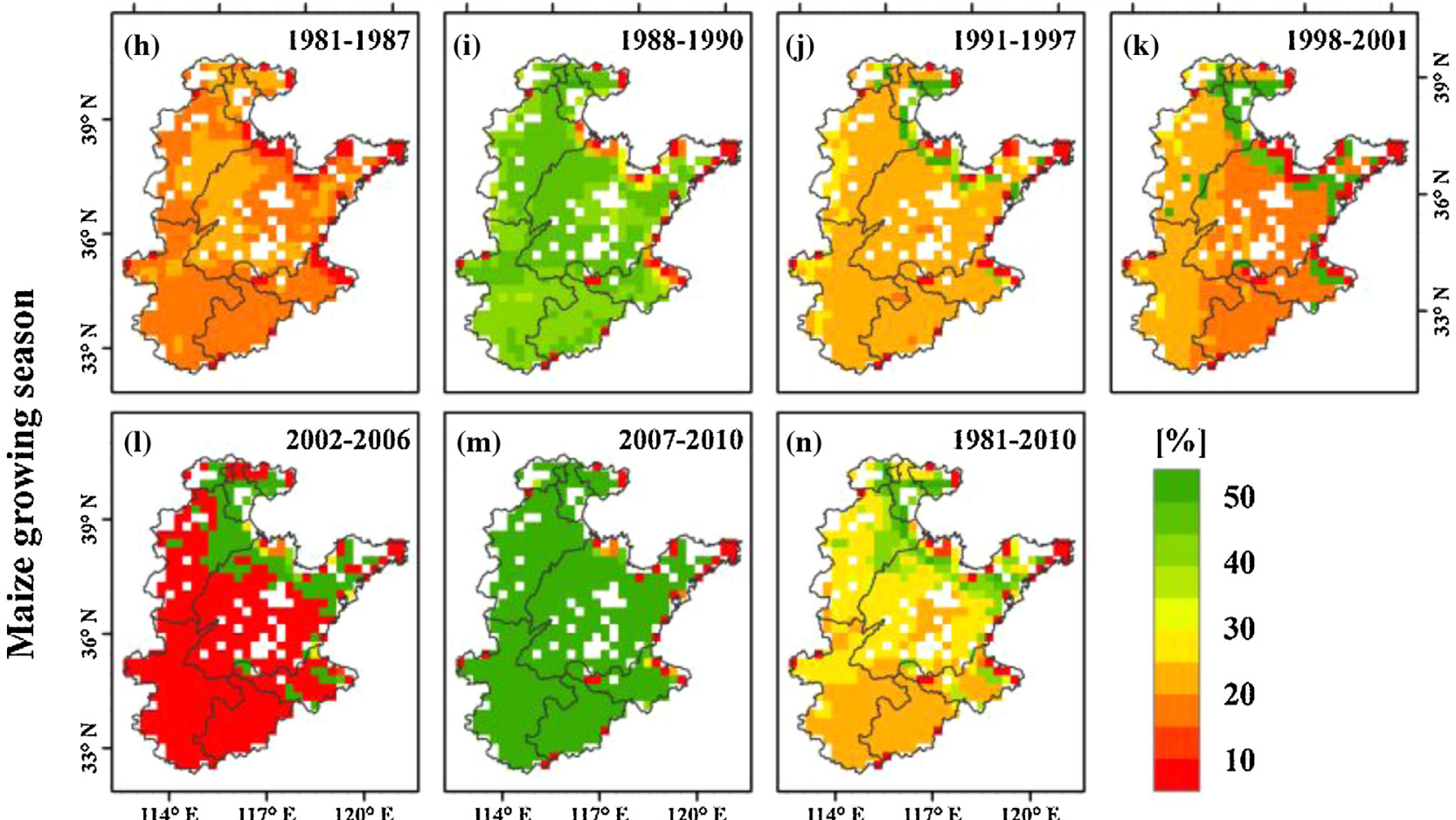

[\%]

50

40

30

20

10

Fig. 2. Spatial availabilities (Percentage of days with available soil moisture data and the total days) of Essential Climate Variable soil moisture data for different blending periods in wheat and maize growing seasons during 1981-2010 over North China Plain (black solid line is the provincial boundary).

tal problems relating to overexploitation of groundwater. In order to conserve the groundwater and ensure the agricultural sustainability, it has taken many water conservation countermeasures, such as adopting water saving irrigation techniques, modified cropping system and developing the desalination industry in coastal region. These countermeasures not only improve crop water-use efficiency, but also change the regional SM pattern.

\subsection{Data}

\subsubsection{ECV SM data}

The ECV SM dataset is derived from the combination of two active (AMI: Active Microwave Instrument; ASCAT) and four passive microwave radiometer sensors (SMMR: the Nimbus 7 Scanning Multi-channel Microwave Radiometer; SSM/I: the Special Sensor 

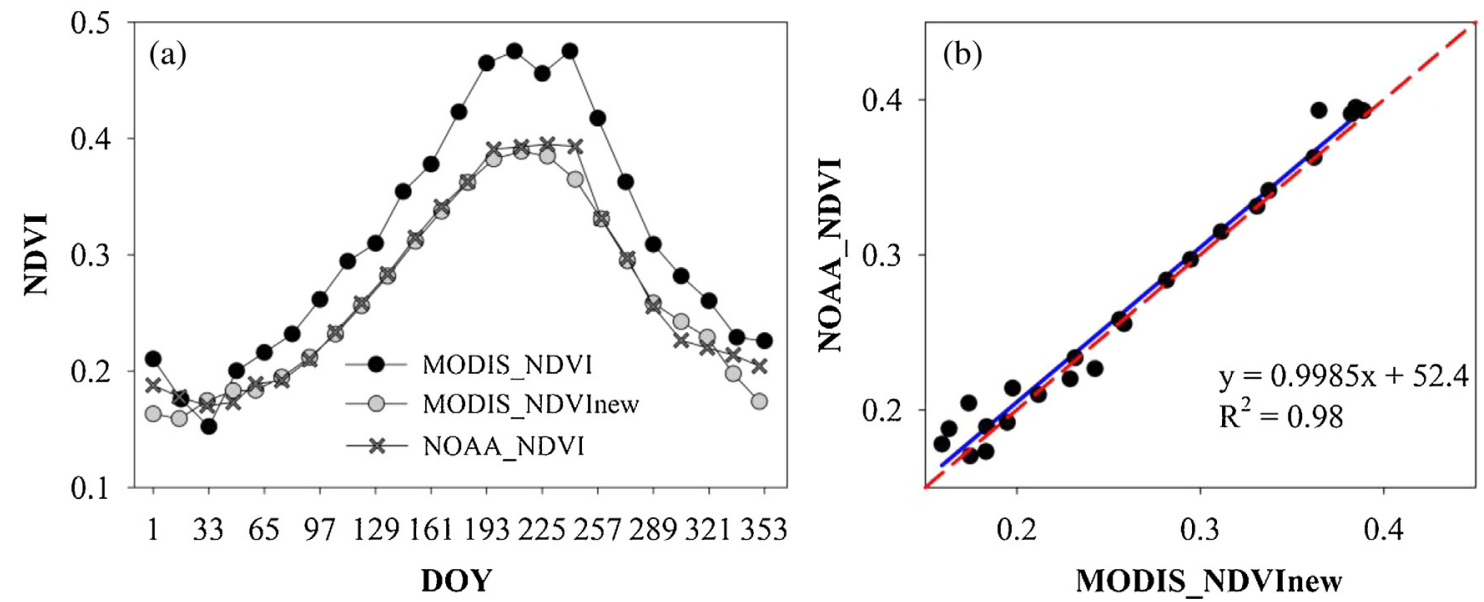

Fig. 3. Comparison of MODIS NDVI before and after linear regression, and NOAA NDVI in 2005. (a) Seasonal variation; (b) scatter plot.

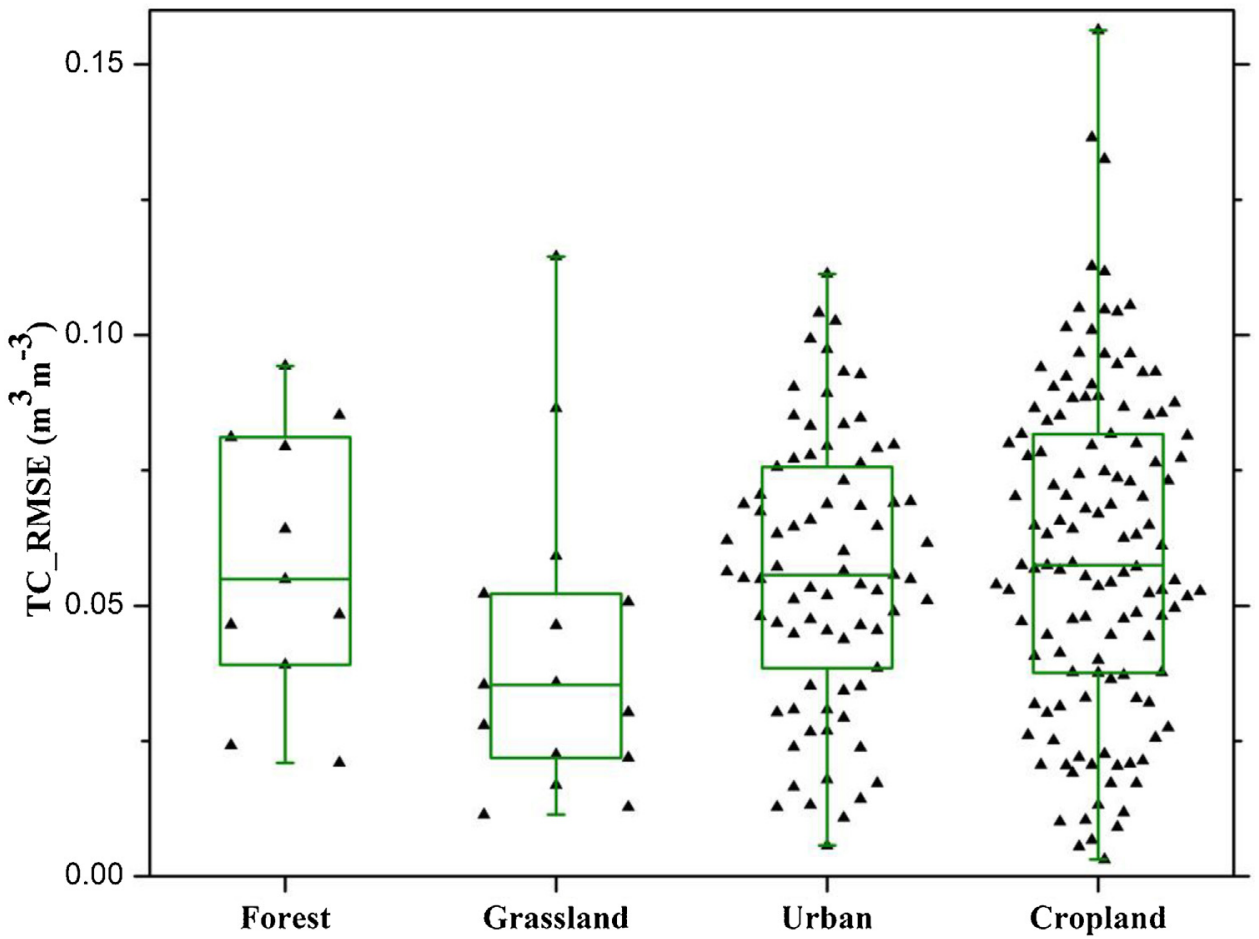

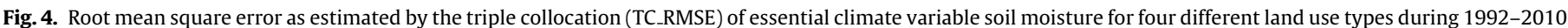

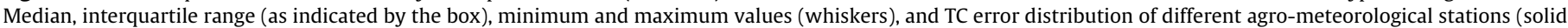
up-triangle) are presented.

Microwave Imagers; TMI: the Tropical Rainfall Measuring Mission (TRMM) Microwave Imager; AMSR-E). The daily gridded data are produced at $0.25^{\circ}$ spatial resolution from 1978 to 2010 . The temporal coverages and sensor types, which are used for constructing long time series ECV SM, are listed in Table 1. More details, including algorithm and theoretical baseline of data processing, may refer to Liu et al. (2011b) and Liu et al. (2012). This dataset provides a long time series of SM values, but inevitably some values are still lack in some dates. To overcome this weakness, the missing daily SM data were first interpolated using the nearest interpolation method (Nalder and Wein, 1998). Then monthly SM data were retrieved from the daily SM data by computing the average of the images in corresponding month. To analyze SM characteristics in different growing seasons, the monthly data were aggregated into wheat (April-June) and maize (July-September) growing seasons respectively.

Table 1

Sptiotemporal coverage of input products used to construct essential climate variable soil moisture.

\begin{tabular}{|c|c|c|c|}
\hline Temporal coverage & $1978 / 11-1987 / 08$ & 1987/09-1991/06 & 1991/07-1997/12 \\
\hline Sensor & SMMR & $\mathrm{SSM} / \mathrm{I}$ & SSM/I + AMI-WS \\
\hline Temporal coverage & $1998 / 01-2002 / 06$ & $2002 / 07-2006 / 12$ & $2007 / 01-2010 / 12$ \\
\hline Sensor & $\mathrm{TMI}+\mathrm{AMI}$ & AMSR-E + AMI & AMSR-E + ASCAT \\
\hline
\end{tabular}


Table 2

The saturation capacity of soil moisture with different soil texture types.

\begin{tabular}{ll}
\hline Soil texture type & Saturation capacity $\left(\mathrm{m}^{3} \mathrm{~m}^{-3}\right)$ \\
\hline Sand & 0.385 \\
Loamy sand & 0.410 \\
Sandy loam & 0.435 \\
Silt loam & 0.485 \\
Loam & 0.451 \\
Sandy clay loam & 0.420 \\
Clay loam & 0.476 \\
Silt clay & 0.482 \\
Clay & 0.482 \\
\hline
\end{tabular}

Previous study showed that the time-series gaps and varying record lengths of data potentially affected the analysis results (Loew, 2014). Hence, the spatiotemporal availabilities of ECV SM data in NCP during wheat and maize growing seasons were studied respectively. Fig. 2 presented the percentage of days with available ECV SM data and the total days for the individual blending periods according to Table 1 . The lowest percentages were found during 1981-1987 and 2002-2006, followed by the periods of 1991-1997 and 1998-2001. The highest percentage was found in 2007-2010 and 1998-2001. During the entire period from 1981-2010, the percentage was found less than $20 \%$ in some southern parts over wheat growing season. Poor values also obtained in the coastal areas, the percentage was basically less than $16 \%$. Data availability was better in maize growing season compared with wheat growing season.

\subsubsection{In-situ SM data}

In-situ SM measurements were collected from 247 agrometeorological stations in China during 1992-2010 (http://cdc. cma.gov.cn/). The SM data were measured by the gravimetric method and recorded as a relative ratio to the field capacity. Measurements were taken on 8 th, 18 th, and 28 th days of each month, at depth of $10,20,30,50,70$, and $100 \mathrm{~cm}$. To remove the influence from frozen condition and to focus on the variation of SM in crop growing season, in-situ measurements only from April to September were considered.

In order to unify ECV SM and model predicted SM, the in-situ observed SM data were calculated from relative humidity into volume water content according to Eq. (2) with saturation capacity of different soil texture type (see Table 2 ).

$\theta_{\mathrm{r}}=\theta_{\mathrm{v}} / \theta_{\mathrm{sa}} \times 100 \%$

$\theta_{\mathrm{v}}=\left(\theta_{\mathrm{r}} \times \theta_{\mathrm{sa}}\right) / 100 \%$

Here $\theta_{\mathrm{r}}$ is relative humidity (unit: degree of saturation\%); $\theta_{\mathrm{V}}$ is volume water content (unit: $\mathrm{m}^{3} \mathrm{~m}^{-3}$ ); and $\theta_{\mathrm{sa}}$ is saturation capacity (unit: $\mathrm{m}^{3} \mathrm{~m}^{-3}$ ).

\subsubsection{Simulated SM data}

The simulated SM data obtained by VIP (vegetation interface processes) model were used as an independent data set for the triple collocation. VIP as a biogeophysical process-based model was designed to simulate land surface energy partitioning and hydrological cycling, crop growth, and soil organic matter decomposition (Mo et al., 2012, 2009). The model has been validated and applied for prediction of crop evapotranspiration and yield over NCP (Mo et al., 2009, 2014). In this model, soil is divided into six layers and SM transfer is described with Richards' equation. Here SM in $0-10 \mathrm{~cm}$ soil layer simulated by VIP model (VIP SM) from 1981 to 2010 in China was used.

\subsubsection{NDVI data}

The global inventory modeling and mapping studies (GIMMS) AVHRR NDVI dataset and MODIS NDVI dataset MOD13A2 were used in this study. The improved version of Savitzky-Golay filter (a) Growing season (April - September)

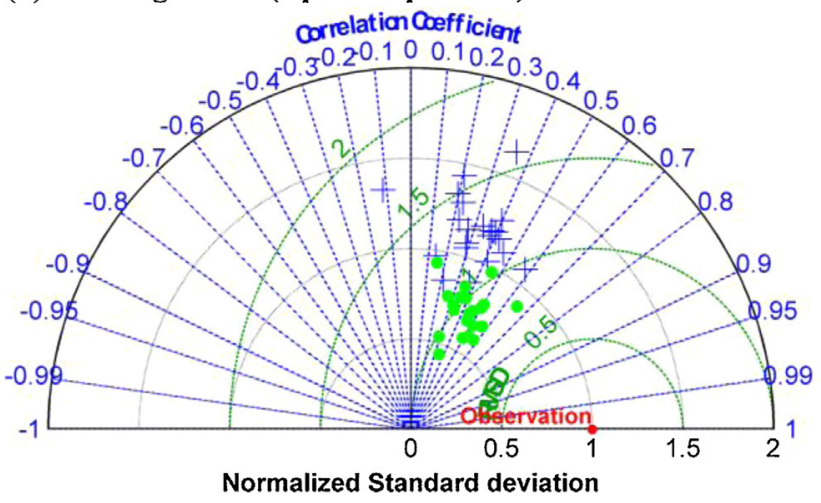

(b) Wheat growing season (April - June)

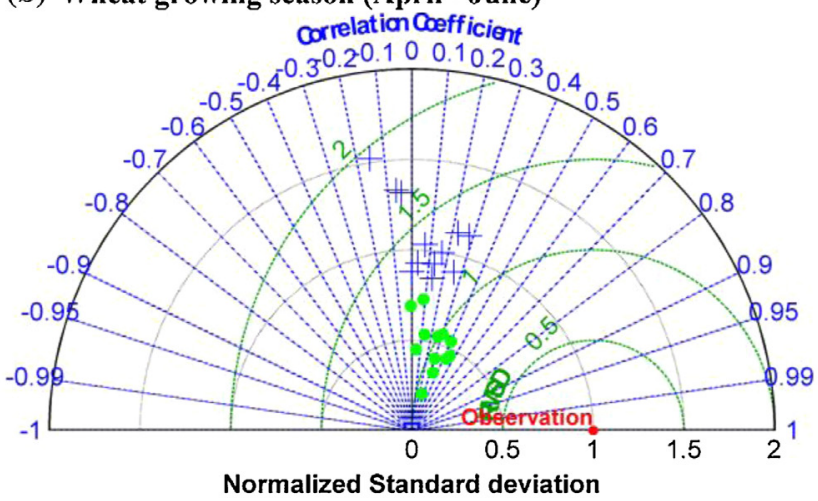

(c) Maize growing season (July - September)

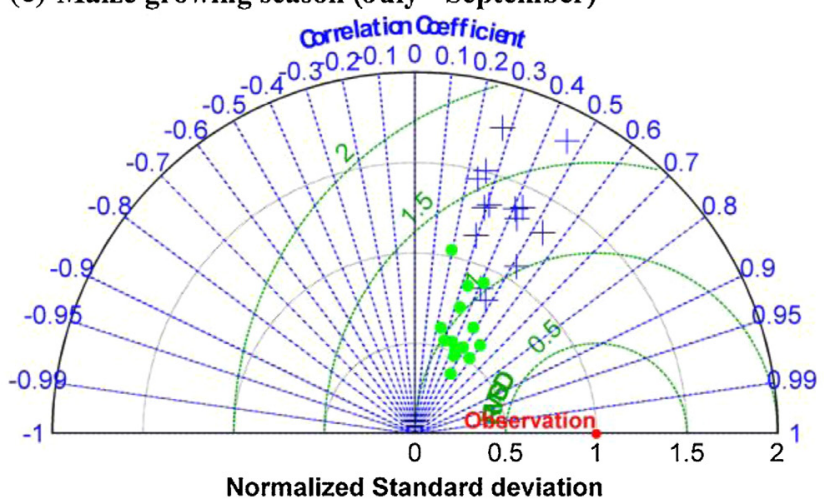

Fig. 5. Taylor diagram of the correlation between essential climate variable soi moisture (green circles), VIP model simulated soil moisture (blue cross), and in-situ soil moisture during 1992-2010: (a) growing season (April-September), (b) wheat growing season (April-June), and (c) maize growing season (July-September).

provided by Chen et al. (2004) was used here for further reducing the NDVI noise.

To be compatible with the AVHRR NDVI time series, MODIS NDVI series were adjusted. The overlapped time for both NDVI series were from 2000 to 2006, among which the data in 2005 were selected randomly for validation. Thus, the data in 6 years (2000-2004, 2006) were used for conducting the linear regression by pixels. First, MOD13A2 data were interpolated from every 16 days to biweekly as the same as GIMMS data by Lagrange interpolation method. Then the regression coefficients $a$ and $b$ were calculated by each pixel as:

$\mathrm{NDVI}_{\mathrm{AVHRR}}=a+b \times \mathrm{NDVI}_{\mathrm{MODIS}}$

And last, the AVHRR NDVI and MODIS NDVI after regression (both in 2005) were used to validate the regression result (Fig. 3). 
Table 3

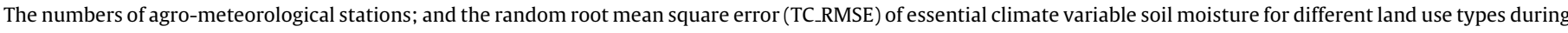
1992-2010.

\begin{tabular}{|c|c|c|c|}
\hline Land use type & Definition of land use type & Numbers of stations & TC_RMSE $\left(\mathrm{m}^{3} \mathrm{~m}^{-3}\right)$ \\
\hline Forest & Land covered with trees and shrubs & 11 & 0.058 \\
\hline Grassland & Land where grass grows and is the dominant form of plant life & 15 & 0.042 \\
\hline Cropland & Land used for the cultivation of crops & 125 & 0.060 \\
\hline Urban construction land & Land used for urban construction & 77 & 0.057 \\
\hline Total/mean & & 228 & 0.054 \\
\hline
\end{tabular}

Table 4

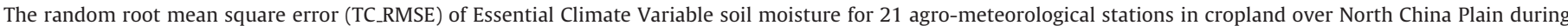
1992-2010.

\begin{tabular}{|c|c|c|c|c|c|}
\hline Station & Numbers of samples & TC_RMSE $\left(\mathrm{m}^{3} \mathrm{~m}^{-3}\right)$ & Station & Numbers of samples & TC_RMSE $\left(\mathrm{m}^{3} \mathrm{~m}^{-3}\right)$ \\
\hline Tongxian & 252 & 0.053 & Jiyang & 140 & 0.085 \\
\hline Bazhou & 125 & 0.105 & Taian & 87 & 0.036 \\
\hline Baodi & 185 & 0.052 & Zibo & 130 & 0.063 \\
\hline Shenzhou & 70 & 0.041 & Hanting & 68 & 0.095 \\
\hline Hejian & 134 & 0.084 & Xuchang & 64 & 0.048 \\
\hline Jinghai & 181 & 0.090 & Qixian & 104 & 0.021 \\
\hline Nangong & 157 & 0.047 & Xihua & 77 & 0.087 \\
\hline Fucheng & 206 & 0.050 & Caoxian & 90 & 0.085 \\
\hline Dezhou & 0.078 & Mengcheng & 60 & 0.067 & \\
\hline Huimin & 160 & 0.082 & Fuyang & 60 & 0.113 \\
\hline Liaocheng & 114 & 0.070 & Mean & & 0.069 \\
\hline
\end{tabular}

After validation, the MODIS NDVI from 2007 to 2010 were adjusted using Eq. (3).

\subsubsection{Auxiliary data}

Potential evapotranspiration (PET) were calculated according to the Penman-Monteith Formula. Actual ET data were simulated by the VIP model (Mo et al., 2014). The daily meteorological data from 1981 to 2010 obtained from China meteorological data sharing service system (http://cdc.cma.gov.cn/) were used to drive VIP model. The land use type data at scale 1:100000 were obtained from data centre for resources and environmental sciences (http:// www.resdc.cn/) of Chinese Academy of Sciences. Soil texture data were retrieved from the map at the scale of 1:14000000 (Institute of Soil Science, Chinese Academy of Sciences, 1986). The irrigation map downloaded from FAO website (http://www.fao.org/) depicts the area equipped for irrigation facilities in percentage of cell area.

\subsection{Analysis methods}

The triple collocation (TC) technique (Dorigo et al., 2015; Miralles et al., 2010; Stoffelen, 1998) was used for estimating the root mean square error (RMSE) of ECV SM dataset, and in this paper, the RMSE derived by TC technique was called TC_RMSE. TC technique is based on the assumption that through an addictive and multiplicative bias component and a random error term, the estimation of SM is related to the hypothetical real SM which is unknown (Stoffelen, 1998). By using three independent datasets of the same geophysical quantity, ECV SM was compared with in-situ SM and VIP SM in this study. The main equation is as follows (Scipal et al., 2008):

$e_{\mathrm{ECV}}=\sqrt{\left[\left(\theta_{\mathrm{ECV}}-\theta_{\mathrm{STA}}\right)\left(\theta_{\mathrm{ECV}}-\theta_{\mathrm{VIP}}\right)\right]}$

where, $e_{\mathrm{ECV}}$ is the TC_RMSE of ECV SM; $\theta_{\mathrm{ECV}}, \theta_{\mathrm{STA}}$, and $\theta_{\mathrm{VIP}}$ are the estimated value of ECV SM, in-situ SM, and VIP SM respectively.

The three complementary statistics standard deviation, RMSE, and correlation coefficient of ECV SM and VIP SM are presented on two-dimensional plots of Taylor diagrams (Taylor, 2001). The nonparametric Mann-Kendall (M-K) test (Yue and Wang, 2004) was applied to analyze the trends and significances of SM and other influencing factors.

\section{Results}

\subsection{Validation ECV SM dataset with in-situ SM and VIP SM}

Previous study has shown that the performance of TC method is closely related to the number of triplets (Zwieback et al., 2012), thus, the stations with triplets less than 50 (14 stations) were not considered in this study. And considering the meaningless and few samples, the stations set up around water body ( 3 stations) and unutilized land (2 stations) were also excluded. Thus in-situ SM measurements in 228 agro-meteorological stations with different land use types were chosen to validate ECV SM. The correlation coefficient between ECV SM and in-situ SM for all stations was 0.42 $(p<0.01)$. TC_RMSEs of ECV SM among different land use types were similar and the averaged TC_RMSE of all 228 stations was $0.054 \mathrm{~m}^{3} \mathrm{~m}^{-3}$ (Table 3). Most strikingly, the cropland had both the highest $\left(0.156 \mathrm{~m}^{3} \mathrm{~m}^{-3}\right)$ and lowest $\left(0.003 \mathrm{~m}^{3} \mathrm{~m}^{-3}\right)$ TC_RMSE (Fig. 4), which was probably caused by the largest number of stations in croplands and their wide distribution in China compared to other land use types.

The statistics of the comparison between ECV SM, VIP SM, and in-situ SM during 1992-2010 for growing season, wheat growing season and maize growing season are shown in the Taylor diagram (Fig. 5). In the entire growing season, correlation between ECV SM and in-situ SM at all stations is significantly positive $(p<0.05)$. The averaged Spearman correlation coefficients $(r)$ are 0.43 and 0.34 for ECV SM and VIP SM. The normalized standard deviations of both ECV SM and VIP SM are mostly below 1.0, which indicates the narrower spread of these two estimates than in-situ SM measurements. The averaged $r$ between ECV SM and in-situ SM is similar in wheat and maize growing season. And the $r$ between VIP SM and in-situ SM is larger in maize than that in wheat growing season. Moreover, the normalized standard deviation of ECV SM is slightly more centered on 1.0 than those of VIP SM, indicating the variation ranges of the former are more similar to in-situ SM than the latter. TC_RMSEs in 21 stations of cropland over NCP are presented in Table 4. The triplets of the 21 stations are around 60-252. There is a large variation in 
Table 5

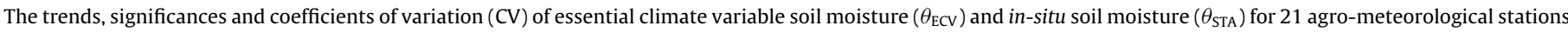
in cropland over North China Plain during 1992-2010.

\begin{tabular}{|c|c|c|c|c|}
\hline Station & Trend of $\theta_{\mathrm{STA}}\left(10^{-4} \mathrm{~m}^{3} \mathrm{~m}^{-3}\right)$ & Trend of $\theta_{\mathrm{ECV}}\left(10^{-4} \mathrm{~m}^{3} \mathrm{~m}^{-3}\right)$ & CV of $\theta_{\text {STA }}(\%)$ & $\mathrm{CV}$ of $\theta_{\mathrm{ECV}}(\%)$ \\
\hline Tongxian & $11.11^{\mathrm{a}}$ & $2.38^{\mathrm{a}}$ & 27.01 & 33.80 \\
\hline Bazhou & $4.44^{\mathrm{a}}$ & -0.74 & 20.75 & 25.31 \\
\hline Baodi & $13.97^{\mathrm{a}}$ & $4.37^{\mathrm{a}}$ & 24.17 & 31.02 \\
\hline Shenzhou & $42.56^{\mathrm{a}}$ & $7.89^{a}$ & 29.31 & 30.44 \\
\hline Hejian & $17.50^{\mathrm{a}}$ & $6.33^{\mathrm{a}}$ & 21.46 & 29.60 \\
\hline Jinghai & $11.45^{\mathrm{a}}$ & $1.98^{\mathrm{a}}$ & 19.54 & 28.62 \\
\hline Nangong & 7.95 & $4.87^{a}$ & 36.18 & 31.60 \\
\hline Fucheng & $19.55^{\mathrm{a}}$ & $5.55^{\mathrm{a}}$ & 42.83 & 30.20 \\
\hline Dezhou & $5.55^{\mathrm{a}}$ & $2.94^{\mathrm{a}}$ & 24.92 & 24.53 \\
\hline Huimin & 0.00 & $4.42^{\mathrm{a}}$ & 17.32 & 24.64 \\
\hline Liaocheng & $22.24^{\mathrm{a}}$ & $6.75^{\mathrm{a}}$ & 20.73 & 27.47 \\
\hline Jiyang & $12.49^{\mathrm{a}}$ & $4.88^{*}$ & 14.56 & 23.47 \\
\hline Taian & $33.18^{\mathrm{a}}$ & $10.08^{\mathrm{a}}$ & 25.14 & 25.50 \\
\hline Zibo & $5.65^{\mathrm{a}}$ & 4.22 & 19.58 & 28.99 \\
\hline Hanting & $37.95^{\mathrm{a}}$ & $16.06^{a}$ & 22.56 & 21.41 \\
\hline Xuchang & $31.22^{\mathrm{a}}$ & $15.73^{\mathrm{a}}$ & 27.02 & 33.99 \\
\hline Qixian & $22.56^{a}$ & $9.72^{\mathrm{a}}$ & 23.59 & 28.52 \\
\hline Xihua & 0.00 & 4.35 & 21.72 & 26.38 \\
\hline Caoxian & $26.48^{\mathrm{a}}$ & $17.36^{a}$ & 21.06 & 30.79 \\
\hline Mengcheng & $41.15^{\mathrm{a}}$ & $18.98^{\mathrm{a}}$ & 25.62 & 23.95 \\
\hline Fuyang & 8.08 & 6.64 & 18.62 & 16.39 \\
\hline
\end{tabular}

a Significant at the 0.05 level.

TC_RMSE of ECV SM which is ranged from 0.021 to $0.113 \mathrm{~m}^{3} \mathrm{~m}^{-3}$ and the average value is $0.069 \mathrm{~m}^{3} \mathrm{~m}^{-3}$. Dorigo et al. (2015) evaluated ECV SM by using TC method based on observations of 596 sites and found the average Spearman correlation coefficient between ECV SM and all in-situ observations is 0.43 excluding winter months for the absolute values, and the averaged TC error is $0.04 \mathrm{~m}^{3} \mathrm{~m}^{-3}$.

To find whether the long-term trend of ECV SM was consistent with in-situ SM at footprint scale, the trends of these two datasets and their coefficients of variation (CV) were calculated (Table 5). Except Bazhou station, the trends of in-situ SM and ECV SM in other stations were all consistent, which meant the ECV SM data generally caught the trend of in-situ SM measurements. The CVs of ECV SM and in-situ SM were close to each other. However, CVs of ECV SM in 16 stations were larger than that of in-situ SM, indicating that the degree of dispersion of ECV SM variation was higher than that of in-situ SM.

\subsection{The spatial distribution and trend analysis of ECV SM in NCP}

In wheat growing season, ECV SM decreased from southeast to northwest (Fig. 6b). The largest SM content appeared in south due to plentiful rainfall (Fig. 6a). In the western and northern parts where rainfall and irrigation water is limited, the SM content is relatively low. Similar to SM in wheat growing season, there was a clear decreasing trend for ECVSM from southeast to northwest in maize growing season (Fig. 6f). The SM content was generally greater than that in wheat growing season due to the abundant rainfall in summer (Fig. 6e). The ECV SM in wheat growing season was dominated by decreasing trend over time for all pixels. For the entire dataset of ECV SM, $61.2 \%$ of the trends were negative (i.e. dry). From Fig. $6 \mathrm{c}$, the most prominent drying trends occurred in southern regions where SM was high (Fig. 6b). In maize growing season, SM trends were positive in south and negative in north. The positive trends of ECV SM accounted for $81.7 \%$ of the entire study region.

\subsection{The temporal trend of ECV SM in NCP}

Regionally, there was no obvious trend in the ECV SM during the wheat growing season, where a significant increase $(p<0.05)$ in maize growing season existed (Fig. 7a). The average annual
Table 6

Spearman correlation coefficients ( $r$ value) between essential climate variable soil moisture $\left(\theta_{\mathrm{ECV}}\right)$ and climatic factors in wheat and maize growing seasons over North China Plain during 1981-2010.

\begin{tabular}{lll} 
Climatic factors & \multicolumn{2}{r}{ Value between climatic factors and $\theta_{\mathrm{ECV}}$} \\
\cline { 2 - 3 } & Wheat growing season & Maize growing season \\
\hline PPT & $0.422^{\mathrm{a}}$ & $0.410^{\mathrm{a}}$ \\
PET & $-0.387^{\mathrm{a}}$ & -0.090 \\
ET & 0.041 & 0.229 \\
\hline
\end{tabular}

a Significant at the 0.05 level.

ECV SM content was $0.21 \mathrm{~m}^{3} \mathrm{~m}^{-3}$ with the standard deviation of $0.013 \mathrm{~m}^{3} \mathrm{~m}^{-3}$. And the values for wheat and maize growing seasons were $0.19 \mathrm{~m}^{3} \mathrm{~m}^{-3}$ and $0.25 \mathrm{~m}^{3} \mathrm{~m}^{-3}$ with the standard deviation of $0.013 \mathrm{~m}^{3} \mathrm{~m}^{-3}$ and $0.019 \mathrm{~m}^{3} \mathrm{~m}^{-3}$, respectively. Higher SM content in maize growing season was mainly caused by higher average annual PPT (Fig. 7b) and the positive value of PPT - ET (Fig. 7e). From the M-K test (Fig. 8), the erupting change of SM in wheat growing season was detected in 1992, when the PPT also reached a breakpoint. In maize growing season, both ECV SM and PPT got their breakpoints in 1984 and 2004, when PET and ET had no significant turning points. From Table 6, in wheat growing season PPT and PET explained $42 \%$ and $39 \%$ of ECV SM variance, respectively; but in maize growing season, only PPT is significant related and explained $41 \%$ of ECV SM variance. Weak correlations between ECV SM and ET existed for both crop seasons.

\section{Discussion}

\subsection{Interpolation for the missing SM values}

The missing values of ECV SM limited the continuous analysis of its spatiotemporal variation. Thus, based on the concept of Geostatistics, the missing values have been interpolated in this study. First of all, the nearest interpolation method was used for interpolating daily ECV SM data, which ensured the spatial integrity of the data for carrying out the spatiotemporal trend analysis. The nearest interpolation simply chooses the actual pixel that has its center nearest to the point located in the image. The advantage of this method is that, the interpolated results are more accurate if the missing values are nearer with the original value. Therefore, the 
Table 7

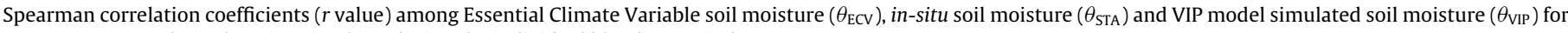
228 agro-meteorological stations in China during the individual blending periods.

\begin{tabular}{|c|c|c|c|}
\hline Analysis period & Number of samples & $r$ Value between $\theta_{\mathrm{STA}}$ and $\theta_{\mathrm{ECV}}$ & $r$ Value between $\theta_{\text {STA }}$ and $\theta_{\text {VIP }}$ \\
\hline 1992-1997 & 5276 & $0.428^{\mathrm{a}}$ & $0.413^{\mathrm{a}}$ \\
\hline $1998-2001$ & 4619 & $0.397^{\mathrm{a}}$ & $0.407^{a}$ \\
\hline 2002-2006 & 6874 & $0.396^{\mathrm{a}}$ & $0.328^{\mathrm{a}}$ \\
\hline 2007-2010 & 15203 & $0.422^{\mathrm{a}}$ & $0.361^{\mathrm{a}}$ \\
\hline $1992-2010$ & 31972 & $0.359^{\mathrm{a}}$ & $0.417^{\mathrm{a}}$ \\
\hline
\end{tabular}

a Significant at the 0.05 level.
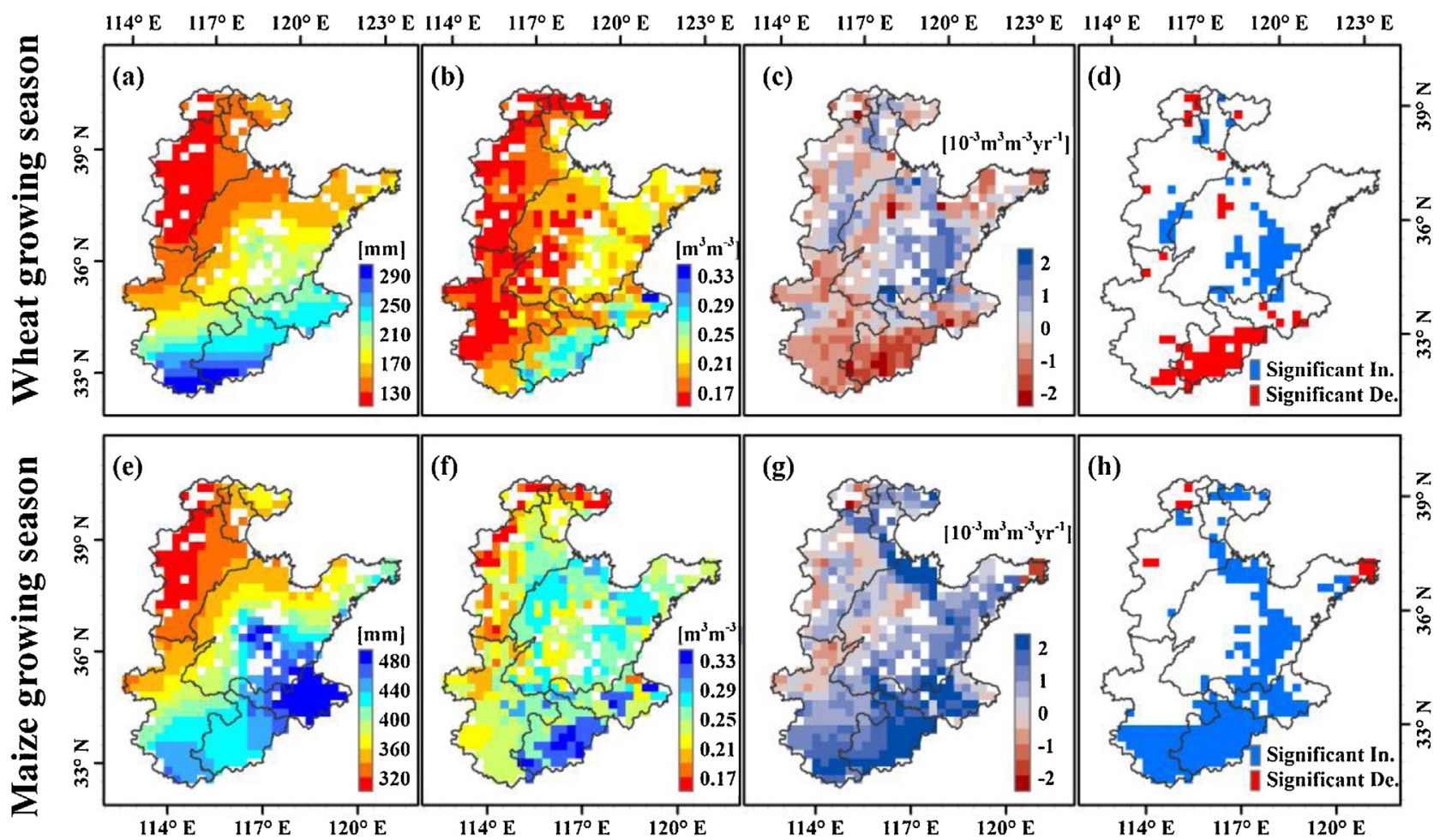

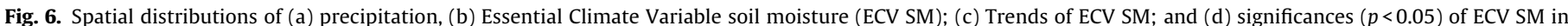

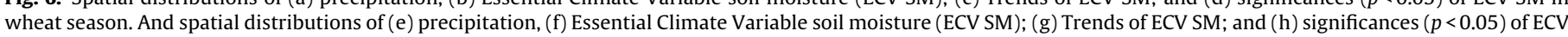
SM in maize season during 1981-2010 over North China Plain (black solid line is the provincial boundary; "In." means "increasing”; and "De." means "decreasing").
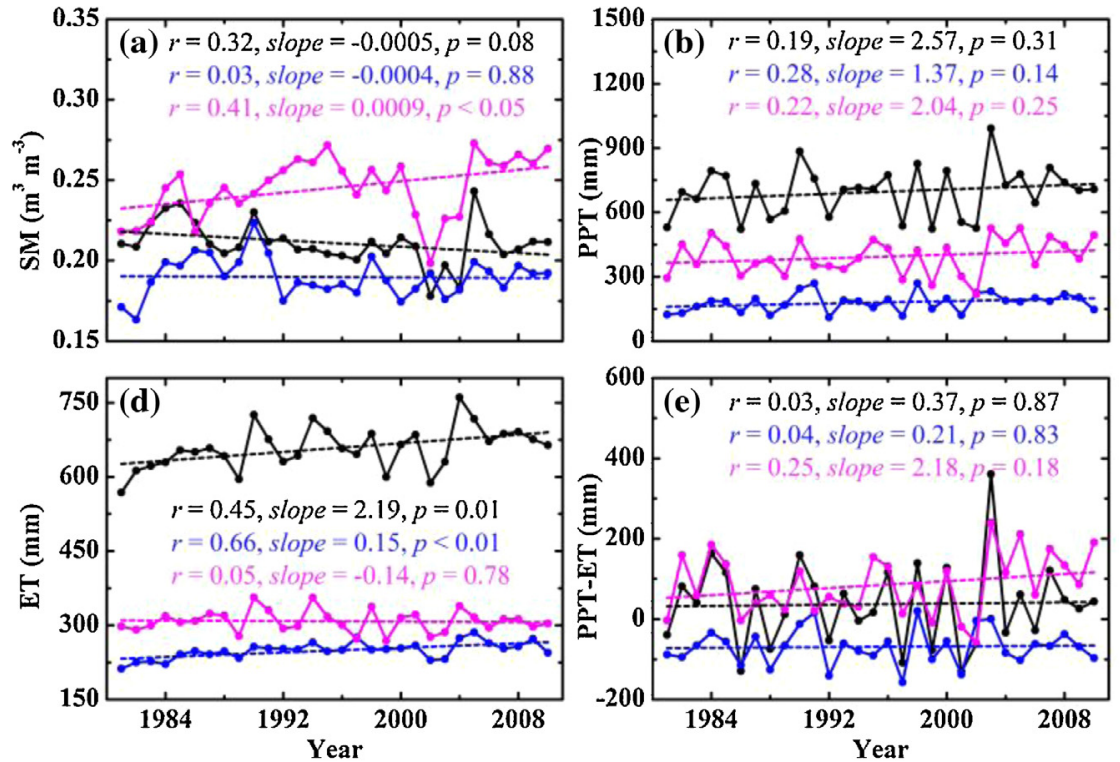

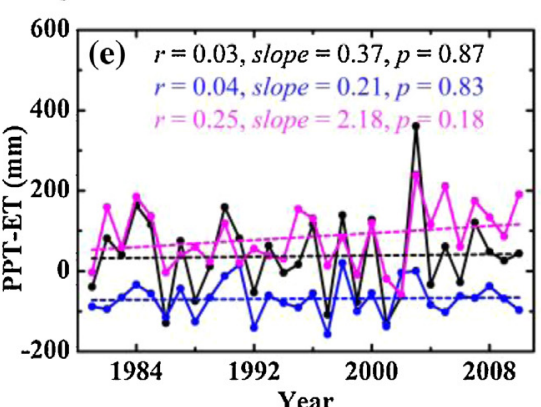

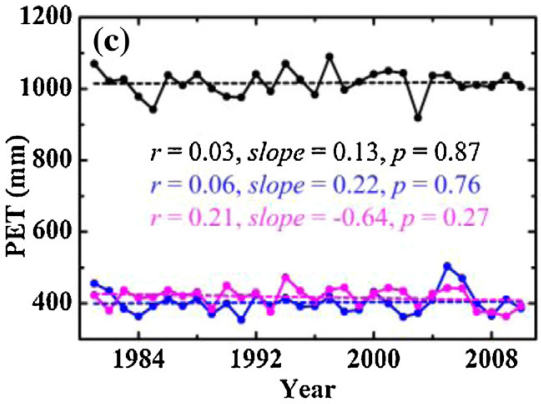

--- Entire year (Janurary-December)

Wheat growing season (April-June)

-- Maize growing season (July-September)

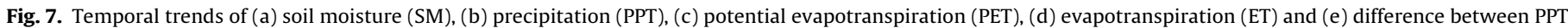
and ET (PET-ET) during 1981-2010 for the entire year, wheat, and maize growing season. 

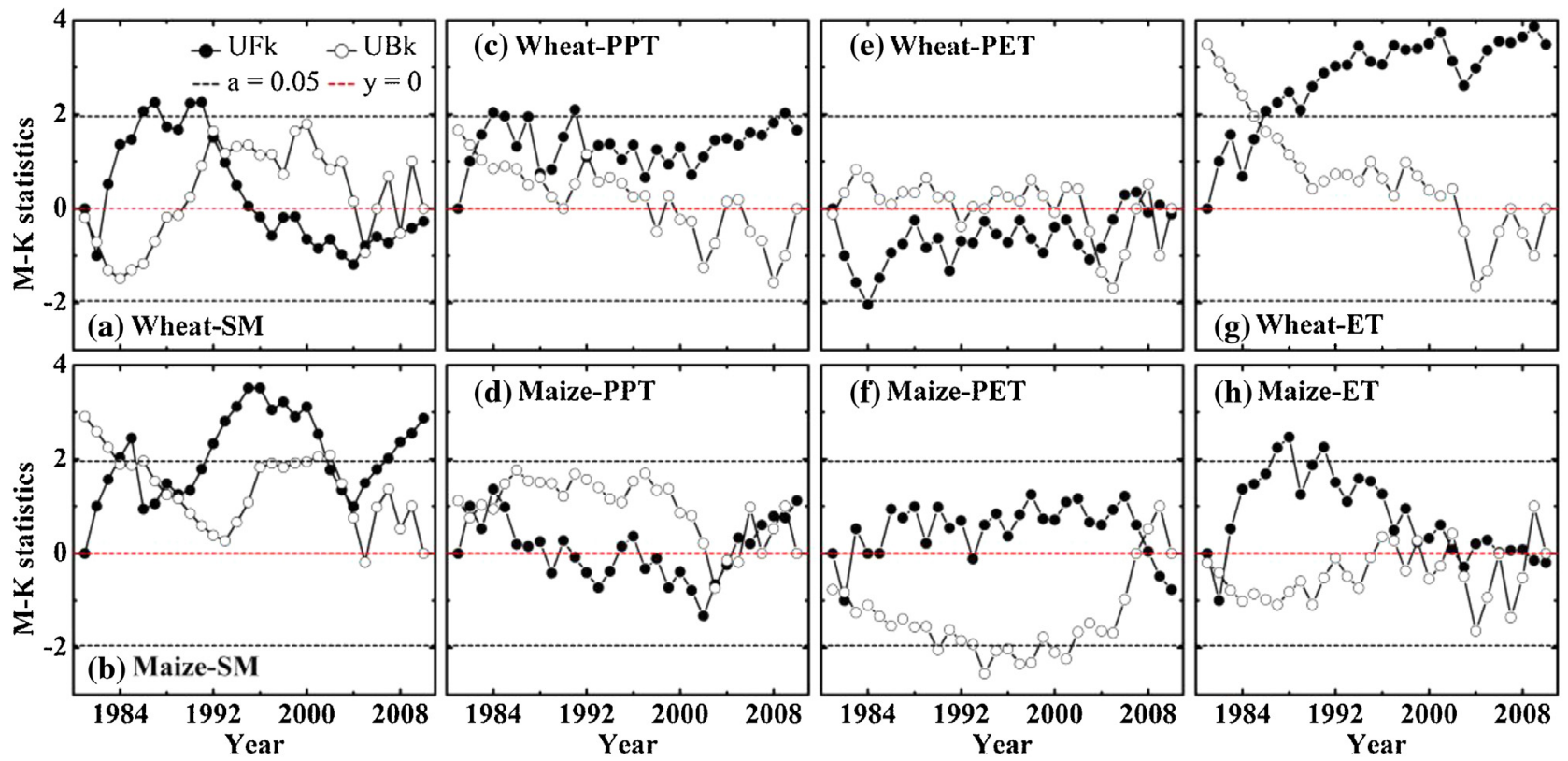

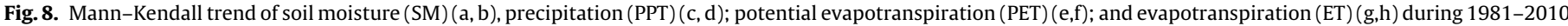
for wheat and maize growing season.

ECV SM VS VIP SM

ECV SM VS NDVI
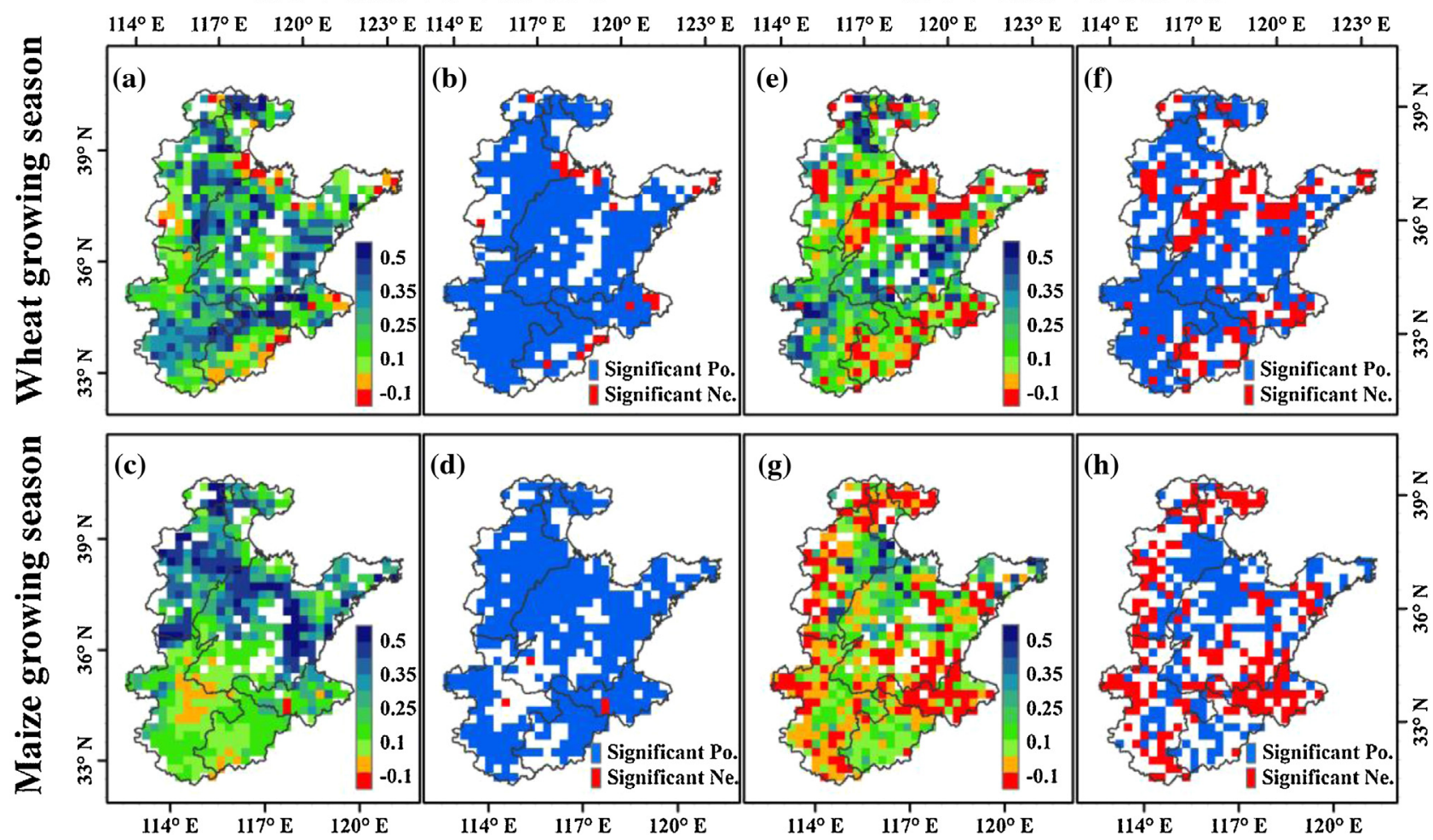

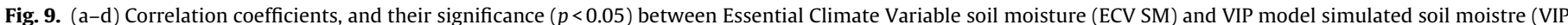

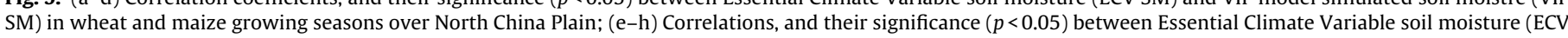

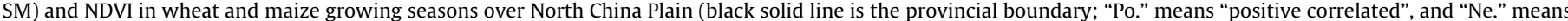
"negative correlated").

Table 8

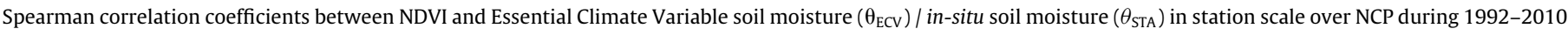

\begin{tabular}{|c|c|c|c|c|c|c|c|c|c|}
\hline Station name & & Langfang & Huanghua & Nangong & Dezhou & Huimin & Linyi & Zhengzhou & Bozhou \\
\hline Correlation & $\theta_{\text {STA }}$ & $0.431^{b}$ & $0.582^{\mathrm{b}}$ & 0.027 & 0.045 & $0.234^{\mathrm{a}}$ & $0.461^{\mathrm{b}}$ & 0.153 & $0.272^{\mathrm{b}}$ \\
\hline & $\theta_{\mathrm{ECV}}$ & $0.713^{b}$ & $0.526^{\mathrm{b}}$ & $0.603^{b}$ & $0.585^{\mathrm{b}}$ & $0.487^{b}$ & $0.490^{\mathrm{b}}$ & $0.528^{\mathrm{b}}$ & $0.393^{b}$ \\
\hline
\end{tabular}

a Significant at the 0.05 level.

b Significant at the 0.01 level. 


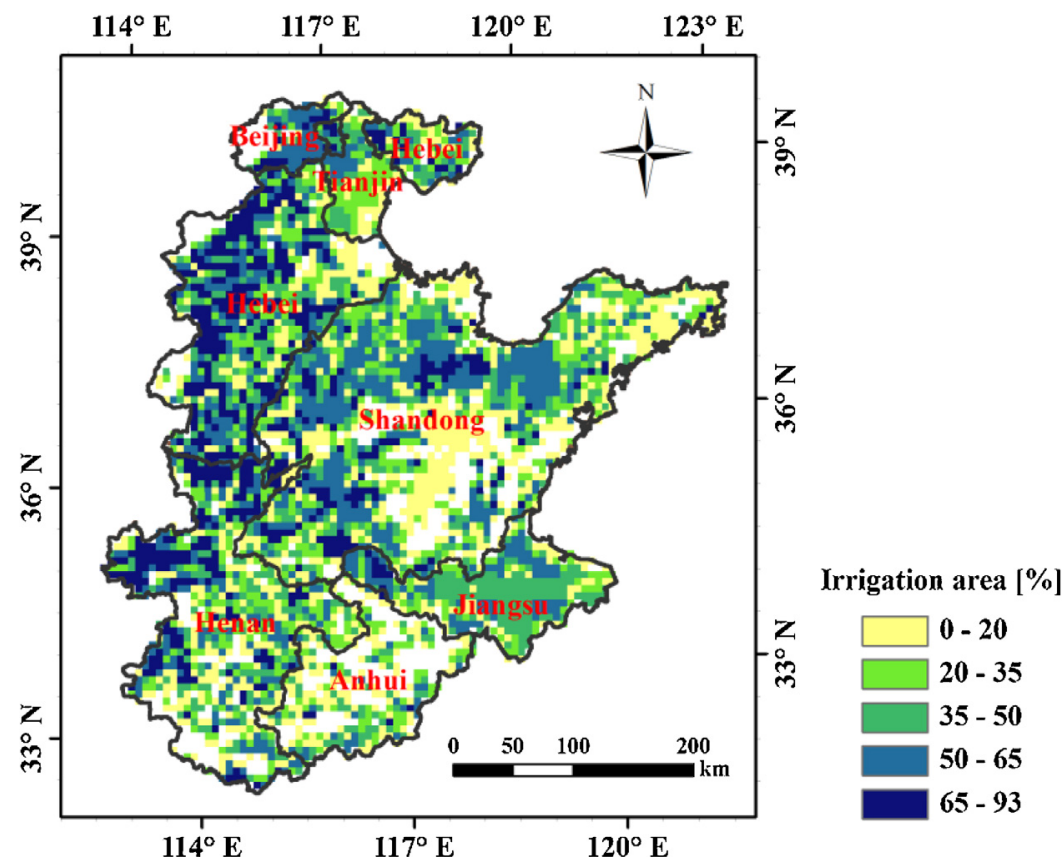

Fig. 10. Irrigation fraction in percentage in North China Plain (black solid line is the provincial boundary).
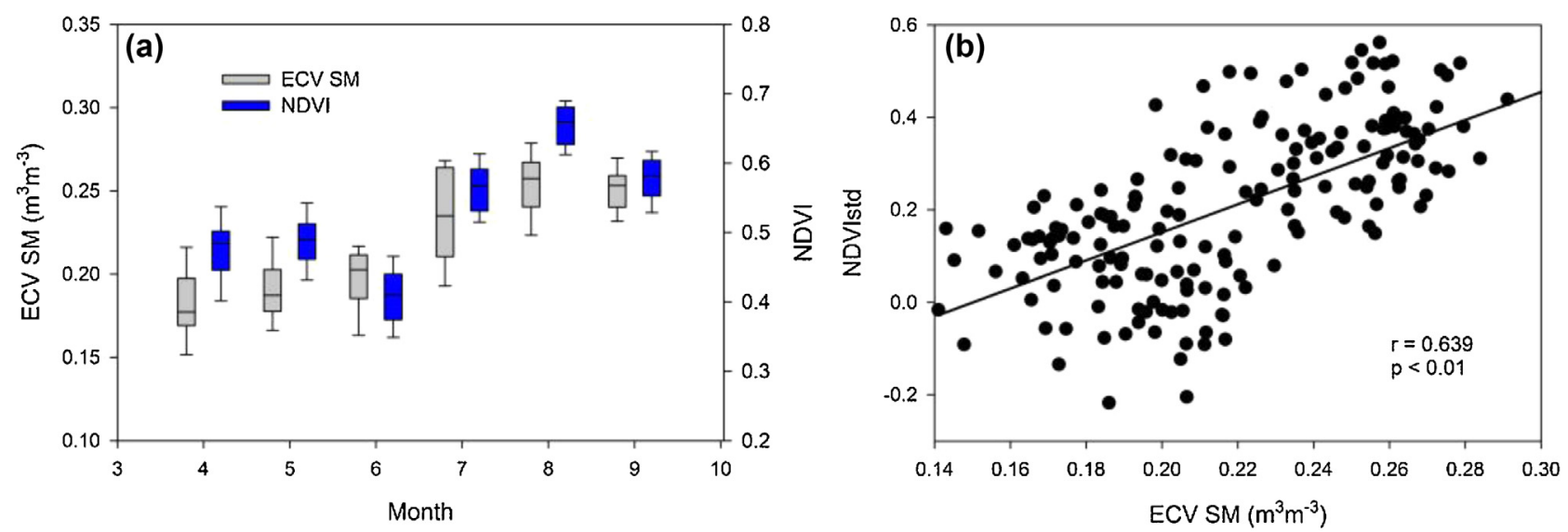

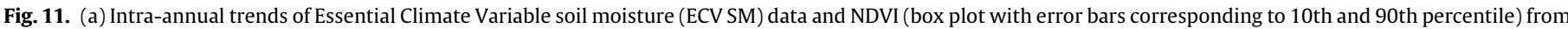
1982 to 2010. (b) Correlation between ECV SM data and standardized NDVI monthly (April-September) during growing season from 1982 to 2010.

analysis results may be influenced if distance between the missing values and original value is greater.

\subsection{Comparing ECV SM dataset with in-situ SM measurements}

The in-situ SM measurements were only available since 1992, thus the performance of ECV SM dataset at agro-met station scale was discussed only during 1992-2010. The results of correlation coefficients between ECV SM, VIP SM and in-situ SM were similar in different study periods (Table 7). It is reported that, as more satellite datasets are available for SM retrieval and the improvement of sensors' performance, the observation density of ECV SM will increase over time, especially after 2002 when the lower quality and coarser resolution C-band observations of SMMR or the Ku- and X-band observations from SSM/I and TMI are replaced by high quality Cband observations with a better suitability for SM retrieval (Dorigo et al., 2015, 2010; Liu et al., 2012; Parinussa et al., 2011). However, the availabilities of ECV SM dataset in NCP during 2002-2006 are rather low both in wheat and maize growing seasons (Fig. 2e, 1), which results in an unfavorable performance of correlation coefficient between ECV SM and in-situ SM. Unexpectedly, the highest availability of ECV SM during 2007-2010 in NCP does not induce the higher correlation with in-situ SM and VIP SM than other periods. When the skill of ECV SM was evaluated by using ground-based SM observations of 596 sites from 28 historical and active monitoring networks worldwide, a consistent decrease of the quality of ECV SM was also found for the period 2007-2010 (Dorigo et al., 2015). Albergel et al. (2013) proved that this phenomenon was caused by the expansion of ECV SM over areas where microwave retrievals are difficult, e.g. over subarctic environments.

\subsection{Comparing ECV SM dataset with VIP SM}

The usual approach for verifying the performance of remotely sensed SM is to use available ground-based measurements. However, considering the sparse networks of in-situ measurements and its less representativeness of spatial varieties across different environment, it is necessary to find new validation methods 
to complement the existing SM networks (Albergel et al., 2013; Wagner et al., 2007). Qiu et al. (2013) found that, the Pearson correlation coefficient between VIP SM simulation and $10 \mathrm{~cm}$ in-situ SM ranged between 0.48 and $0.70(p<0.01)$, and unbiased RMSE ranged between 0.032 and $0.054 \mathrm{~m}^{3} \mathrm{~m}^{-3}$. They also suggested that, VIP SM showed good agreements with high temporal resolution in-situ SM from experimental site and rainfall stimulation. Thus, VIP SM was used as a reference to monitor the consistency of the ECV SM product. The averaged correlation coefficient between VIP SM and in-situ SM in NCP during 1992-2010 was $0.417(p<0.01)$. It is shown that in the study area, the two datasets were $91 \%$ and 95\% positively correlated in wheat (Fig. 9a, b) and maize (Fig. 9c, d) growing seasons, respectively, which meant ECV SM was generally consistent with model predicted SM in most areas of NCP. The negative or relative low positive correlations were found mainly in the areas with poor data availability of ECV SM according to Fig. 2(h, $\mathrm{n})$, which was possibly affect the interpolation reliability.

\subsection{Comparing ECV SM dataset with NDVI}

The spatial relationship between ECV SM and NDVI is diverse at regional scale (Fig. 9e, g). The correlation coefficients between ECV SM and NDVI are poorer in maize season than that in wheat season, which may be caused by the higher vegetation density in maize season. Dorigo et al. (2010) explained that the Ku-band observations from SSM/I during 1988-1990 were able to provide valuable SM over sparsely vegetated areas. Recent studies also show that, over the continental USA and Canada, AMSR-E SM data are more reliable in areas with less vegetation impact, based on the comparison with in situ network and land-surface model (Champagne et al., 2010; Hain et al., 2011). The SM in cropland is often influenced by anthropogenic effects, such as improvement of agricultural technology, management level and irrigation. The negative correlation coefficients between ECV SM and NDVI (Fig. 9f, h) mainly happen in the areas with higher irrigation amount (Fig. 10) accompanied with higher management level, which affect the relationship between NDVI and ECV SM.

NDVI is sensitive to climate change and vegetation drought response (Atkinson et al., 2011). To test whether the variation and trend of ECV SM can reflect the actual response of crop to water limitation for the root zone SM, the intra-annual and inter-annual correlations between NDVI and ECV SM were analyzed in the growing season from 1982 to 2010 on monthly basis. The mean ECV SM responded predictably to NDVI, with two evident peaks of wave representing the wheat-maize cropping system (Fig. 11a). In order to compare the consistency of inter-annual variations between ECV SM and NDVI, the correlation between ECV SM and standardized NDVI is shown in Fig. 11b. The two datasets basically show good relationship with Pearson coefficient of $0.64(p<0.01)$, indicating the ECV SM is a good indicator of NDVI. When analyzing the correlation between ECV SM, in-situ SM and NDVI at agro-met station scale, ECV SM showed higher correlation coefficient with NDVI than in-situ SM (Table 8), reflecting the scale mismatched between the three datasets.

\section{Conclusions}

The essential climate variable (ECV) remotely sensed soil moisture (SM) dataset was firstly validated using SM observations at 228 agro-meteorological stations in China and 21 stations in North China Plain (NCP) for cropland. Then, its spatiotemporal variation and influencing factors were analyzed among different crop growing seasons during 1981-2010 in NCP. And by combining the model simulated SM and NDVI, the reliability of ECV SM trend analysis was explored.
Results showed that the average triple collocation random error of ECV SM for all stations in China was $0.052 \mathrm{~m}^{3} \mathrm{~m}^{-3}$. ECV SM was generally comparable to in-situ measurements with correlation coefficients of $0.43(p<0.01)$ for cropland over NCP. Spatially, ECV SM in NCP decreased from southeast to northwest both in wheat and maize growing seasons. The trends of ECV SM agreed better with that of predicted SM by VIP model in maize growing season. Regionally, in wheat growing season PPT and PET explained $42 \%$ and $39 \%$ of ECV SM variance, respectively; but in maize growing season, only PPT explained $41 \%$ of ECV SM variance. In both wheat and maize growing periods, correlations between ECV SM and ET were low. The high correlation coefficient between ECV SM and standardized NDVI demonstrates that ECV SM is suitable to study SM changes in the root zone in cropland.

Evaluation of ECV remotely sensed product in China especially for cropland presents that ECV SM potentially capture the temporal dynamics of cropland's soil moisture and can be used to monitor regional soil moisture variation at seasonal and inter-annual scales.

\section{Acknowledgments}

This study was jointly supported by the Natural Science Foundation of China grants $(31171451,41471026)$. We are grateful to the availability of the ECV soil moisture dataset from ESA website. We would like to thank Dr. Muhammad Hasan Ali Baig, editors and two anonymous reviewers who provided thorough and constructive suggestions.

\section{References}

Albergel, C., Dorigo, W., Balsamo, G., Muñoz-Sabater, J., de Rosnay, P., Isaksen, L., Brocca, L., de Jeu, R., Wagner, W., 2013. Monitoring multi-decadal satellite earth observation of soil moisture products through land surface reanalyses. Remote Sens. Environ. 138, 77-89.

Atkinson, P.M., Dash, J., Jeganathan, C., 2011. Amazon vegetation greenness as measured by satellite sensors over the last decade. Geophys. Res. Lett. 38 (19), L19105.

Brocca, L., Hasenauer, S., Lacava, T., Melone, F., Moramarco, T., Wagner, W., Dorigo, W., Matgen, P., Martínez-Fernández, J., Llorens, P., Latron, J., Martin, C., Bittelli, M., 2011. Soil moisture estimation through ASCAT and AMSR-E sensors: an intercomparison and validation study across Europe. Remote Sens. Environ. 115 (12), 3390-3408.

Champagne, C., Berg, A., Belanger, J., McNairn, H., Jeu, R.D., 2010. Evaluation of soil moisture derived from passive microwave remote sensing over agricultural sites in Canada using ground-based soil moisture monitoring networks. Int. J. Remote Sens. 31 (14), 3669-3690

Chen, J., Jönsson, P., Tamura, M., Gu, Z., Matsushita, B., Eklundh, L., 2004. A simple method for reconstructing a high-quality NDVI time-series data set based on the Savitzky-Golay filter. Remote Sens. Environ. 91 (3), 332-344.

Cho, E., Choi, M., 2014. Regional scale spatio-temporal variability of soil moisture and its relationship with meteorological factors over the Korean peninsula. J. Hydrol. 516 (17), 317-329.

Choi, M., 2012. Evaluation of multiple surface soil moisture for Korean regional flux monitoring network sites: advanced microwave scanning radiometer $\mathrm{E}$, land surface model, and ground measurements. Hydrol. Process. 26 (4), 597-603.

Dorigo, W., de Jeu, R., Chung, D., Parinussa, R., Liu, Y., Wagner, W., Fernández-Prieto D., 2012. Evaluating global trends $(1988-2010)$ in harmonized multi-satellite surface soil moisture. Geophys. Res. Lett. 39 (18), L18405.

Dorigo, W.A., Gruber, A., De Jeu, R.A.M., Wagner, W., Stacke, T., Loew, A., Albergel, C., Brocca, L., Chung, D., Parinussa, R.M., Kidd, R., 2015. Evaluation of the ESA CCI soil moisture product using ground-based observations. Remote Sens. Environ. 162, 380-395.

Dorigo, W.A., Scipal, K., Parinussa, R.M., Liu, Y.Y., Wagner, W., de Jeu, R.A.M., Naeimi, V., 2010. Error characterisation of global active and passive microwave soil moisture datasets. Hydrol. Earth Syst. Sci. 14 (12), 2605-2616.

Figa-Saldaña, J., Wilson, J.J.W., Attema, E., Gelsthorpe, R., Rnkwater, M., Stoffelen, A., 2002. The advanced scatterometer (ASCAT) on the meteorological operational (MetOp) platform: a follow on for European wind scatterometers. Can. J. Remote Sens. 28 (3), 404-412.

Grayson, R.B., Western, A.W., Chiew, F.H.S., Blöschl, G., 1997. Preferred states in spatial soil moisture patterns: local and nonlocal controls. Water Resour. Res. 33 (12), 2897-2908.

Hain, C.R., Crow, W.T., Mecikalski, J.R., Anderson, M.C., Holmes, T., 2011. An intercomparison of available soil moisture estimates from thermal infrared and passive microwave remote sensing and land surface modeling. J. Geophys. Res. 116 (D15). 
Jackson, T.J., Cosh, M.H., Bindlish, R., Starks, P.J., Bosch, D.D., Seyfried, M., Goodrich, D.C., Moran, M.S., Du, J., 2010. Validation of advanced microwave scanning radiometer soil moisture products. IEEE Trans. Geosci. Remote Sens. 48 (12), 4256-4272.

Juglea, S., Kerr, Y., Mialon, A., Wigneron, J.P., Lopez-Baeza, E., Cano, A., Albitar, A., Millan-Scheiding, C., Carmen Antolin, M., Delwart, S., 2010. Modelling soil moisture at SMOS scale by use of a SVAT model over the Valencia anchor station. Hydrol. Earth Syst. Sci. 14 (5), 831-846.

Leroy, S.S., Anderson, J.G., Ohring, G., 2008. Climate signal detection times and constraints on climate benchmark accuracy requirements. J. Clim. 21 (4), 841-846.

Li, B., Rodell, M., 2013. Spatial variability and its scale dependency of observed and modeled soil moisture over different climate regions. Hydrol. Earth Syst. Sci. 17 (3), 1177-1188

Liu, Y.Y., de Jeu, R.A.M., McCabe, M.F., Evans, J.P., van Dijk, A.I.J.M., 2011a. Global long-term passive microwave satellite-based retrievals of vegetation optical depth. Geophys. Res. Lett. 38 (18), L18402.

Liu, Y.Y., Dorigo, W.A., Parinussa, R.M., de Jeu, R.A.M., Wagner, W., McCabe, M.F. Evans, J.P., van Dijk, A.I.J.M., 2012. Trend-preserving blending of passive and active microwave soil moisture retrievals. Remote Sens. Environ. 123, 280-297.

Liu, Y.Y., Parinussa, R.M., Dorigo, W.A., De Jeu, R.A.M., Wagner, W., van Dijk, A.I.J.M. McCabe, M.F., Evans, J.P., 2011b. Developing an improved soil moisture dataset by blending passive and active microwave satellite-based retrievals. Hydrol. Earth Syst. Sci. 15 (2), 425-436.

Loew, A., 2014. Terrestrial satellite records for climate studies: how long is long enough? A test case for the Sahel. Theor. Appl. Clim. 115 (3-4), 427-440.

Loew, A., Stacke, T., Dorigo, W., de Jeu, R., Hagemann, S., 2013. Potential and limitations of multidecadal satellite soil moisture observations for selected climate model evaluation studies. Hydrol. Earth Syst. Sci. 17 (9), 3523-3542.

Mahmood, R., Hubbard, K.G., 2003. Simulating sensitivity of soil moisture and evapotranspiration under heterogeneous soils and land uses. J. Hydrol. 280 (1-4), 72-90.

Miralles, D.G., Crow, W.T., Cosh, M.H., 2010. Estimating spatial sampling errors in coarse-scale soil moisture estimates derived from point-scale observations. J. Hydrometeorol. 11 (6), 1423-1429.

Mo, X., Liu, S., Lin, Z., 2012. Evaluation of an ecosystem model for a wheat-maize double cropping system over the North China Plain. Environl. Modell. Softw. 32 (5), 61-73.

Mo, X., Liu, S., Lin, Z., Guo, R., 2009. Regional crop yield, water consumption and water use efficiency and their responses to climate change in the North China Plain. Agric. Ecosyst. Environ. 134 (1-2), 67-78.

Mo, X., Liu, S., Meng, D., Lin, Z., 2014. Exploring the interannual and spatia variations of ET and GPP with climate by a physical model and remote sensing data in a large basin of Northeast China. Int. J. Climatol. 34 (6), 1945-1963.

Nalder, I.A., Wein, R.W., 1998. Spatial interpolation of climatic normals: test of a new method in the Canadian boreal forest. Agric. For. Meteorol. 92 (4), 211-225.

Orth, R., Seneviratne, S.I., 2013. Propagation of soil moisture memory to streamflow and evapotranspiration in Europe. Hydrol. Earth Syst. Sci. 17 (10), 3895-3911.
Parinussa, R.M., Meesters, A.G., Liu, Y.Y., Dorigo, W., Wagner, W., de Jeu, R.A., 2011 Error estimates for near-real-time satellite soil moisture as derived from the land parameter retrieval model. IEEE Geosci. Remote Sens. 8 (4), 779-783.

Pratola, C., Barrett, B., Gruber, A., Kiely, G., Dwyer, E., 2014. Evaluation of a global soil moisture product from finer spatial resolution SAR data and ground measurements at Irish sites. Remote Sens. 6 (9), 8190-8219.

Qiu, J., Mo, X., Liu, S., Lin, Z., Yang, L., Song, X., Zhang, G., Naeimi, V., Wagner, W., 2013. Intercomparison of microwave remote-sensing soil moisture data sets based on distributed eco-hydrological model simulation and in situ measurements over the North China Plain. Int. J. Remote Sens. 34 (19), 6587-6610.

Qiu, J., Mo, X., Liu, S., Lin, Z., 2014. Exploring spatiotemporal patterns and physical controls of soil moisture at various spatial scales. Theor. Appl. Clim. 118 (1-2), 159-171.

Qiu, Y., Fu, B., Wang, J., Chen, L., 2001. Spatial variability of soil moisture content and its relation to environmental indices in a semi-arid gully catchment of the Loess Plateau, China. J. Arid Environ. 49 (4), 723-750.

Rebel, K.T., de Jeu, R.A.M., Ciais, P., Viovy, N., Piao, S.L., Kiely, G., Dolman, A.J., 2012. A global analysis of soil moisture derived from satellite observations and a land surface model. Hydrol. Earth Syst. Sci. 16 (3), 833-847.

Santer, B.D., Mears, C., Doutriaux, C., Caldwell, P., Gleckler, P.J., Wigley, T.M.L. Solomon, S., Gillett, N.P., Ivanova, D., Karl, T.R., Lanzante, J.R., Meehl, G.A., Stott, P.A., Taylor, K.E., Thorne, P.W., Wehner, M.F., Wentz, F.J., 2011. Separating signal and noise in atmospheric temperature changes: the importance of timescale. J. Geophys. Res. 116 (D22), D22105.

Savva, Y., Szlavecz, K., Carlson, D., Gupchup, J., Szalay, A., Terzis, A., 2013. Spatial patterns of soil moisture under forest and grass land cover in a suburban area, in Maryland, USA. Geoderma 192, 202-210.

Scipal, K., Holmes, T., De Jeu, R., Naeimi, V., Wagner, W., 2008. A possible solution for the problem of estimating the error structure of global soil moisture data sets. Geophys. Res. Lett. 35 (24), 101-106.

Stoffelen, A., 1998. Toward the true near-surface wind speed: error modeling and calibration using triple collocation. J. Geophys. Res. 103 (C4), 7755-7766.

Taylor, K.E., 2001. Summarizing multiple aspects of model performance in a single diagram. J. Geophys. Res. 106 (D7), 7183-7192.

Wagner, W., Bloschl, G., Pampaloni, P., Calvet, J.-C., Bizzarri, B., Wigneron, J.-P., Kerr, Y., 2007. Operational readiness of microwave remote sensing of soil moisture for hydrologic applications. Nord. Hydrol. 38 (1), 1-20.

Wagner, W., Naeimi, V., Scipal, K., Jeu, R., Martínez-Fernández, J., 2006. Soil moisture from operational meteorological satellites. Hydrogeol. J. 15 (1), $121-131$.

Yue, S., Wang, C., 2004. The Mann-Kendall test modified by effective sample size to detect trend in serially correlated hydrological series. Water Resour. Manag. 18 (3), 201-218.

Zwieback, S., Scipal, K., Dorigo, W., Wagner, W., 2012. Structural and statistical properties of the collocation technique for error characterization. Nonlin. Processes Geophys. 19 (1), 69-80. 